\title{
More than one way to flip a class: learning analytic for mixed models of learning
}

\author{
Alan Dix \\ University of Birmingham and Talis
}

\begin{abstract}
This case study presents personal experiences in the reuse of materials, originally prepared for a small-scale MOOC, in face-to-face flipped-classroom and blended learning teaching. While some of the literature on the flipped classroom suggests a quite uniform pedagogic style for each class, albeit differing between advocates, the experience of the author was far more pedagogically diverse, depending on the type of material and workload of the students. Fine-grain learning analytics were also critical; these both allowed targeted feedback (enhancing student learning) and gave a sense of control (enhancing academic motivation and well-being).
\end{abstract}

Keywords: learning analytics, flipped classroom, video, MOOC, learning-resource reuse

\section{Introduction}

The flipped classroom is at the confluence of multiple digital technologies. These include technologies for: (i) the creation and sharing of reusable and, possibly, open educational resources; (ii) the delivery and consumption of those resources on multiple platforms, possibly adapted for or augmented by learners; (iii) the monitoring and analysis of usage, progress and achievement. However, unlike online learning, the flipped classroom is set within a matrix of face-to-face contact and personal engagement.

There is a level of continuity and discontinuity in these technologies.

Those who have been involved in education for some years will be aware of research including intelligent teaching systems almost as old as computers; lecture augmentation and video capture in Classroom2000/eClass since the early 1990s (Abowd, 1999) and mlearning almost as far back. Crucially, the ubiquity and low cost of web delivery led to a high-level institutional push towards digital delivery from the mid- to late-1990s, sadly driven less by pedagogic goals than by financial considerations - though the latter were usually misguided.

So, while the term 'flipped classroom' is new, both the underlying idea and much of the supporting technology are very familiar.

However, there clearly is a difference in the last few years, both in terms of fully-online learning, notably the MOOC revolution, and flipped-classroom practice. This is due in part to the speed and availability of video editing and web delivery (the YouTube effect), in part to the ubiquity of devices able to deliver online resources and in part to the changing expectations and skills of students being brought up with social media (UCL, 2008).

In order to study these changing styles of learning, the author delivered a small MOOC in 2013 and then reused the video materials as part of flipped teaching at his university in late 2014 and early 2015. The latter also enabled him to try for himself a new universal media 
player developed by Talis, which enables a more consistent user experience and provides detailed usage analytics - 'micro level' in Buckingham Shum's (2012) terms.

The next section outlines some of the background to this work and, in particular, some details of the MOOC materials. It then looks at the outcomes, particularly the diversity of styles of use of the material in flipped-class (and related) styles of teaching and the importance of fine-grained learning analytics in supporting pedagogy and offering a sense of academic control.

\section{Context: from textbook to MOOC to flipped class}

The author was involved in the management of one of the early post-graduate courses in technology-enhanced learning (MSc in Technology for Learning, Staffordshire University, 1996). He is also an author of one of the main international textbooks in Human Computer Interaction (Dix et al, 2004). This textbook provides substantial additional online and tutor materials, including PowerPoint slides, mini-case studies, exercises with sample answers and multiple-choice questions; that is material primarily for reuse by other tutors.

However, despite this theoretical knowledge and practical experience in provision of materials for wide-spread learning, he had not, until recently, been personally involved in the actual delivery of distance learning, rich blended learning, nor, critically, flipped-classroom teaching.

In 2013, a small-scale MOOC was prepared and delivered, which covered partly material in the $\mathrm{HCl}$ textbook and partly new material. One of the reasons for doing this was to gain experience with the pedagogic and technical challenges of MOOC production and, in particular, the creation of video material that could potentially be reused by others in their own teaching.

The MOOC material was dominated by video - nearly thirty hours, corresponding roughly to the amount of lecture time in a typical one-semester course. This was broken into ten units, each equivalent to about one week of a face-to-face course. However, only the first six out of the ten units were actually used in the MOOC, as it became rapidly evident that there was far too much material. In fact, the majority of the students focused on the first two units only, but kept revisiting them for the entire nominal length of the course. The first of these was simply the course introduction and motivation, so effectively the students focused primarily on what corresponded to one week's worth of the material.

In retrospect, it would have been better to have made these three to four hours of video material the entire course, as this was clearly sufficient to fill the intended course duration. This corresponds closely to the volume of material described in the production of FutureLearn MOOCs. Glasgow University's detailed report covers the production and delivery of their first two FutureLearn MOOCs (Kerr et al, 2015); the total video time was only about two to three hours in each of these MOOCs, albeit split into many small two- to three-minute segments.

This highlights a real tension in the delivery of distance material. Older distance-learning models, notably the Open University television programmes produced in the 1970s, were of substantial length; however, the most successful recent MOOCs use not only much shorter segments, but far less total time. Of course, the Glasgow University FutureLearn material 
described above included extensive textual materials, but then so also did the 1970s OU courses; and, of course, face-to-face students are expected to read textbooks as well as attend lectures.

It is important to challenge the common myth of lecture as 'content delivery', which ignores other aspects of the face-to-face experience such as motivation, mutual support and feedback. However, this does not mean that content is not important and a traditional lecture typically reinforces verbally and in slightly different ways the same material that is found in text.

Clearly, the purposes and contexts of students joining a MOOC are not the same as students on more traditional courses, but the massive difference in content quantity raises questions as one moves towards flipped-classroom models.

\section{Why flip? Research and development and pedagogic drivers}

Teachers are driven to adopt the flipped classroom for many different reasons, some individual, some institutional. Rather like the MOOC experience above, the author's first steps in the flipped classroom were as much a research and development (R\&D) agenda about understanding the issues around flipping, as they were pedagogic.

There were two sides to the R\&D agenda.

The first goal was to leverage the availability of the materials produced for the MOOC, described above. As noted, one of the aims in producing the MOOC material was to create reusable resources. Indeed, the material has already been reused to create several courses on the Interaction Design Foundation open education platform (IDF, 2015); it has also been taken up by other educators. By using the materials for his own teaching at University of Birmingham, the author hoped to understand better the advantages and limitations.

Potential advantages are clear. Material created for MOOCs is intended to be read or watched online in a relatively unsupervised distance mode; this has obvious potential for student access prior to face-to-face learning in flipped mode. Also the costs of MOOC production are high, with estimates ranging from fifty thousand dollars to over a quarter of a million dollars per course (Hollands and Tirthali, 2014; DeJong, 2013) with video production between $\$ 2,500$ and $\$ 10,000$ per minute (Hollands and Tirthali, 2014b; Fox, 2010); reuse in face-to-face learning could help amortize this cost and increase the sustainability of MOOCs (Dix, 2015b).

Another R\&D goal was to get experience of using a universal content player being piloted as part of a Talis project, 'Lighthouse'. Talis develops teaching and learning software primarily targeted at higher education. Currently, the Talis reading list and digital content management software are used by eighty-six institutions worldwide, including over half of UK universities.

The Lighthouse player allows video, audio, PDFs, slides and other text and graphic materials to be viewed with, as far as is possible, a uniform user experience (see Figure 1). In addition, the mobile app versions of the player allow students, while connected to a WiFi network, to download videos which can then be viewed offline. Finally, the player includes detailed logging, allowing fine-grained learning analytics. The author is a researcher at Talis 
as well as an academic and the flipped-classroom teaching offered an opportunity to pilot these new features in a real setting.

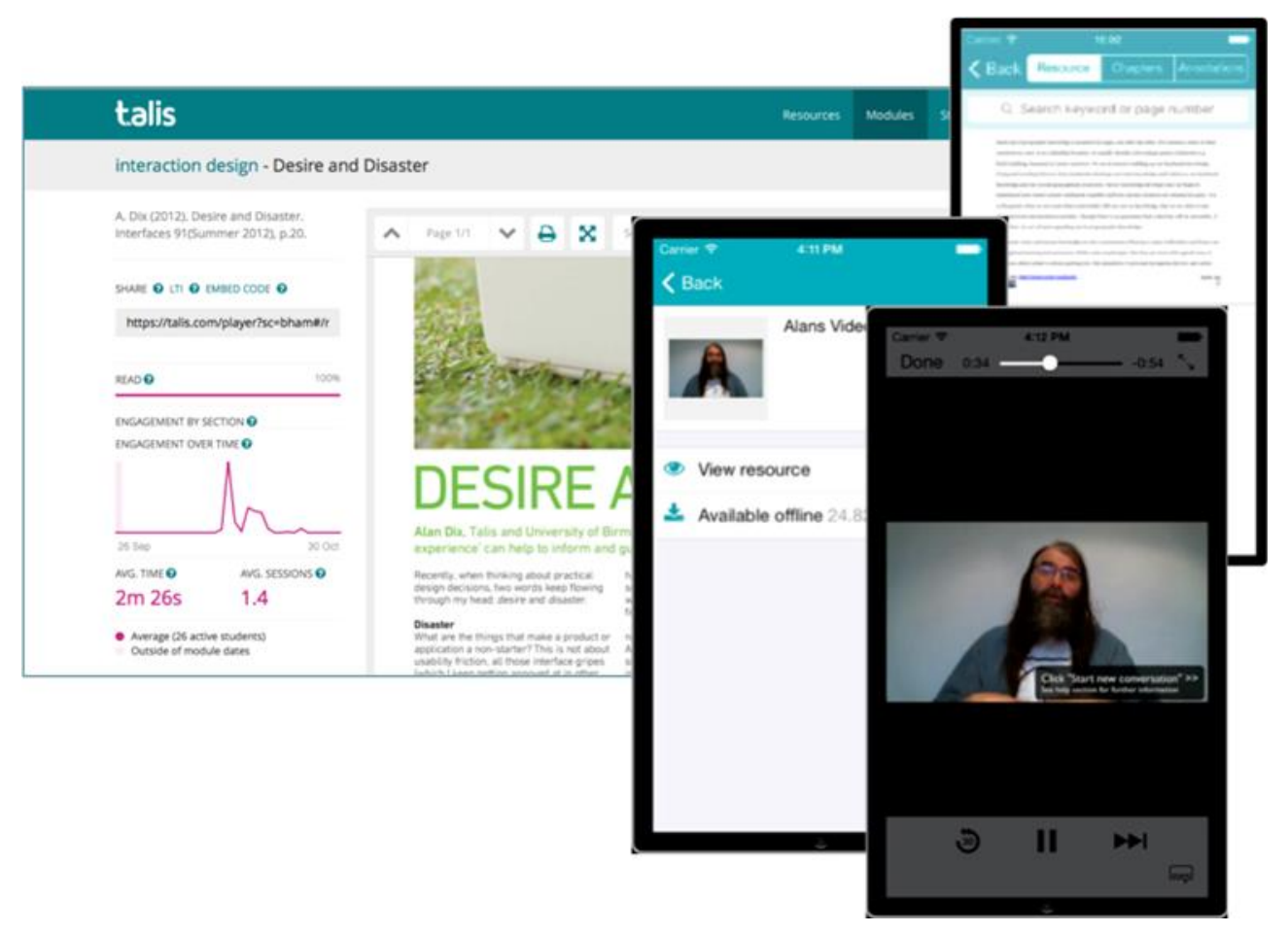

Figure 1: Talis Lighthouse pilot - web and mobile players

There are, of course, many pedagogic reasons for choosing to use flipped-classroom teaching, including better use of face-to-face time, greater student autonomy and more flexible learning - see reviews by Estes et al (2014) and Hamdan et al (2013). However, there are also drawbacks.

Academic time is always scarce and, whilst most academics are used to standing up and delivering a lecture, pre-preparing material takes considerably more time. In particular, while delivering a face-to-face lecture, the teacher can see whether students are understanding and either re-iterate points or adapt pace accordingly. In contrast, when preparing materials for online use, the teacher has to pre-empt perceived potential problems, but may, in the process, risk labouring points that students actually grasp quickly.

This was certainly very evident in preparation of the MOOC videos. While these were very simple, lecture-like head and shoulders over slides, the level of preparation before videoing was considerable. When these were reused for the flipped class, navigating the VLE to add all the materials proved to be time-consuming. The VLE in question, Canvas, was, if anything, easier than other VLEs the author has used at different institutions, but still tedious when adding large volumes of material.

There are also problems of student access. At the APT 2015 Conference, where this work was first presented, a group of drama students prepared a series of sketches, based on interviews with other students, concerning issues of flipped-class and blended learning. While the advantages of flipping were presented, nearly every sketch included access 
issues, such as: (i) lack of access to internet when off campus; (ii) insufficiently powerful student computers and (iii) domestic problems (as viewing videos on a phone was not perceived by other family members as real studying). Given that adequate access to the internet in some areas of the country is still only around $50 \%$, delivering materials online instantly excludes, to some extent, many socially-, geographically- or physicallymarginalised groups.

The above students were from the University of Greenwich, which has a high level of participation of 'under-represented' groups, according to the UK Higher Education Statistics Agency (HESA, 2015). In contrast, University of Birmingham scores disappointingly low in indices of widening participation (82\% compared to Greenwich's $94 \%$ ) and so these access issues were less likely to affect the students in this case study.

Finally, the idea of flipped-class teaching can be little short of terrifying for the academic. Whenever students are asked to study outside class there is a loss of control - will they actually read or watch the suggested material?

\section{Delivery: many modes of flipping}

The MOOC material was used as part of a module ('Advanced Human Computer Interaction') which included a combination of final-year undergraduate students and masters students. We did not teach the entire course using this method, partly because it was new and partly because the overlap in topics between the MOOC and face-to-face module was limited.

One of the main lessons was about diversity (hence this case study's title). Some of the literature on the flipped classroom (e.g. Schell, 2012) suggests a quite uniform pedagogic style for each class, albeit differing between advocates. However, the experience of the author was far more mixed, depending on the type of material and the workload of the students.

In fact, each use had its own unique character, but they seemed to fall into three main classes:

- basics + integration - Although this was an Advanced Human Computer Interaction $(\mathrm{HCl})$ course, the fact that the student group was mixed meant that the participants differed considerably in their level of 'basic' $\mathrm{HCl}$. Preparatory videos were thus used for more basic material and students were told to watch the overview video and then to use their discretion regarding the others. The ensuing lecture then focused more upon integrative concepts. Effectively this constitutes use of the preparatory material as remedial instruction.

- fully flipped - Some classes followed a more standard flipped mode, with video and textual materials before class preceding more discursive in-class material. In one class comprising purely masters students, group discussions seemed far more productive, probably because of both class size and student maturity.

- $\quad$ reinforcement - In some sessions, all material was available on video, but it repeated the in-class teaching. This, in some ways, resembled lecture capture, except that, thanks to the knowledge that everything was available on video, the 
otherwise traditional lecture could be more easily paced and interactive, since the students would be able, from the online material, to fill in gaps.

In the last of these, there was, perhaps unsurprisingly, noticeable attendance fall-off, particularly from the 'back of the class', when students were told in advance that videos covered the same material as in the lecture. Crucially, there was no corresponding hike in the watching of the videos that corresponded to the in-class teaching until the exam period. It appears that weaker or less-motivated students decided that they need not attend the lecture as they could always catch up online later, but did not do so until exam panic set in. This is precisely the reason why some academics have resisted giving to students notes or lecture-capture technology.

This last point emphasises the potential anxiety experience of many academics when considering variations of the flipped classroom. Although, in principle, there are potential pedagogic advantages in offering more student autonomy, this significantly reduces the academic's sense of control over learning. This comes at a time when academics are often facing increased accountability. In the UK, the raising of student fees has paradoxically led to the adoption, by a minority of students, of a more passive, "I've paid, so teach me", attitude to learning (The Guardian, 2015), whilst, at the same time, the UK Government is proposing a 'Teaching Excellence Framework', to assess more closely university-level teaching (UK Government, 2015). As well as other educational benefits, learning analytics offer one way of retaining some element of control during flipped-class teaching.

\section{Analytics: managing panic and developing pedagogy}

Learning analytics are often associated with more high-level management of institutions, where multiple data sources, including test scores, attendance and even library usage, can be collated. However, recent years have seen an additional focus on the use of learning analytics to aid the individual learner and teacher. The Purdue traffic lights system is perhaps the most well-known of these, using a variety of raw data sources to provide students with a simple student dashboard, allowing them to see how well they are doing and suggesting remedial action if they are falling behind (Arnold, 2010). Indeed, Long and Siemens (2011) distinguish between the two kinds of analytics, calling the institutional level 'academic analytics' and reserving 'learning analytics' for department-level or course interventions.

Often the finest level of analytics provided by VLEs are click-through counts, providing the information that a student has viewed a page, opened a video, or downloaded a PDF. However, finer-level information can reveal more: for example, Hibbert (2014) describes how the 'play-through rate' (the average proportion of a video that has been watched) provided by Kaltura can be used to assess whether videos are sufficiently compelling. Currently, few platforms offer this level of detailed analytics: YouTube and Vimeo offer very rich analytics, but all at the level of the whole video; Panopto does allow drilling through to video-frame analytics, but like Kaltura, only for video material.

The Talis Lighthouse player provides fine analytics for each type of media, showing not just what has been viewed, but the parts that have been viewed, and this is available for videos, audio or paged content such as PDFs or slides. The most common pattern is a drop-off where students stop watching or reading at a certain point, but it is instructive to know 
whether a $50 \%$ level of viewing corresponds to everyone watching half, or half watching it all and the rest dropping off after the first minute or so. However, it is also possible to see, for example, where a portion of video has been watched multiple times, or where long dwell time on a certain page of a document suggests that there is some difficulty.

The analytics are immediately available to the tutor when viewing the resource on the player. This can be seen in Figure 2; this is the tutor's view and the basic analytics are visible on the left-hand side of the page. This availability proved to be remarkably effective, even for simple click-through statistics. While VLEs do provide this kind of information, the author had never previously taken the effort to find it; the 'in your face' nature of the analytics (either visible or with a single button), meant that they were viewed and proved surprisingly compelling to watch. Elsewhere, the author has discussed more broadly the way different analytics should fit within different timescales of academic activity and, in particular, the way detection or notification that action is necessary should synchronise with the availability of resources and time for action to occur (Dix and Leavesley, 2015).

These analytics had direct pedagogic benefit, sometimes allowing the author gently to cajole the students ("I know that only half of you have looked at this"), but also to offer more direct guidance. In one case, it was clear that the students were reading only the beginning of a long research paper (see Figure 2); the author was able to advise them that even if they skipped most of the paper, the last section was particularly valuable as it showed the theoretical techniques being applied in practice.

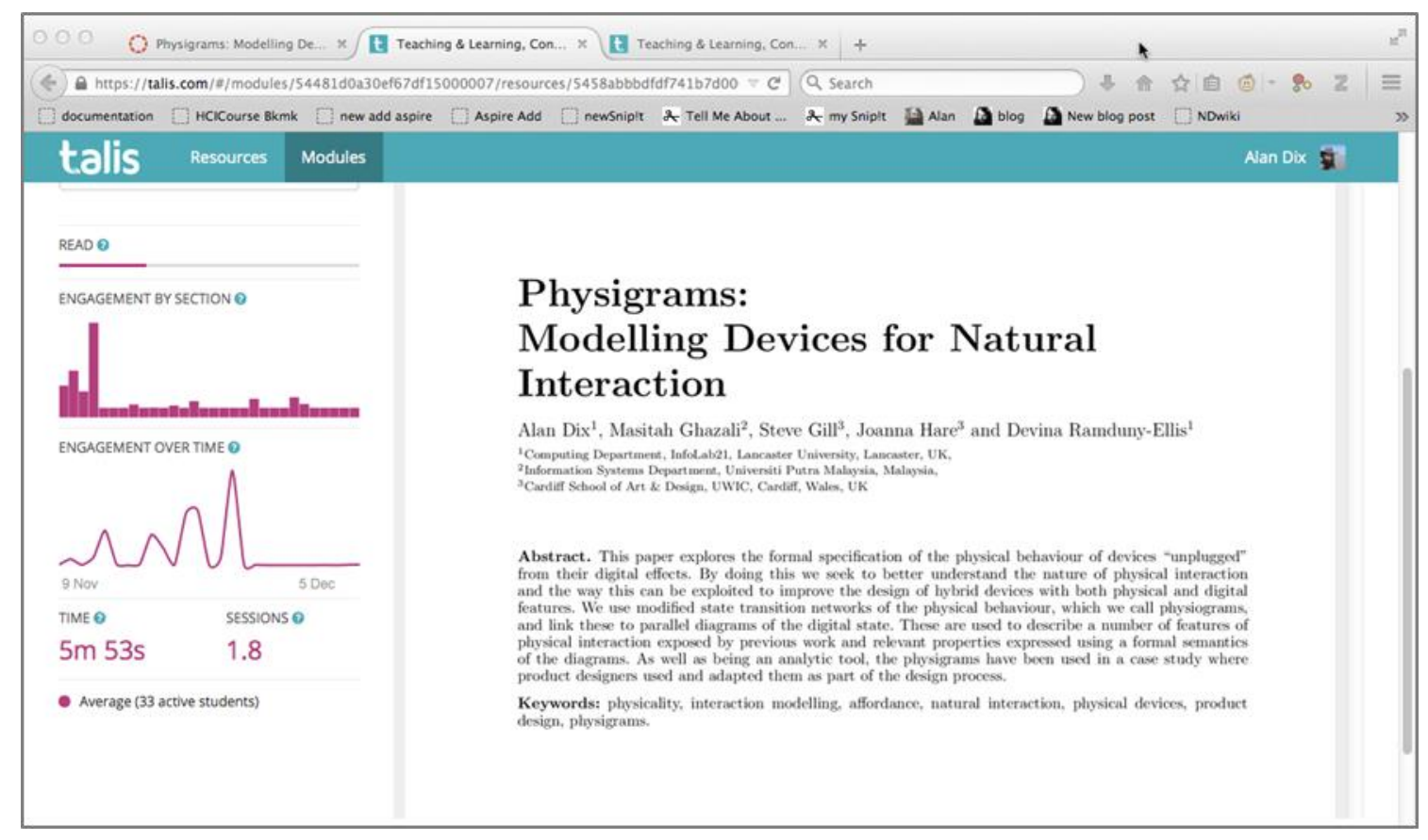

Figure 2: Analytics on PDF document. The 'heat map' at the top left shows which portions of the document have been read.

However, perhaps the most powerful use of the analytics was simply to give the academic a sense of control. As noted, one of the problems of any sort of recommended out-of-class activity is a loss of control for the academic. This is an inevitable consequence of increased student autonomy; however, as previously discussed, this is also coupled with ever-growing external and internal quality regimes and metrics (not least institutional-level analytics) that 
put increased responsibility on the academic to ensure student performance. This combination of increased responsibility and reduced control is a recipe for stress. While the fine-grained analytics do not allow the academic to force students to engage with resources, there is a quite surprising sense of control from being at least able to monitor that engagement.

\section{Conclusions}

This is only a small-scale case study, but does reveal that, even in a single course, there is a wide diversity of possible ways to use materials in variations of flipped-classroom or blended learning. The author's lack of experience in using flipped-classroom methods may account for this, but it feels self-evident that the balance of use of pre-class, in-class and post-class materials will vary, depending on the type of material and workload of the students.

The fine-grain learning analytics, which were available from Talis Player, were critical, allowing targeted feedback and offering a sense of control. While the former is of clear pedagogic value. it is perhaps the latter, control, which is most significant in terms of academic motivation and well-being, a pre-condition to technology adoption and sustainability. As noted, few platforms currently offer this level of analytics and, to the author's knowledge, no others across different media, but it seems likely that given the clear benefits, this will become an essential feature in the near future.

\section{Acknowledgements}

This work was first presented at APT 2015 (Dix, 2015) and has benefited from feedback there, from other talks based on the material and from insightful Compass reviews. Thanks also to colleagues at University of Birmingham and Talis and to my students at Birmingham who suffered my early attempts at flipping.

\section{Reference list}

Abowd, G. (1999) 'Classroom 2000: An Experiment with the Instrumentation of a Living Educational Environment.' IBM Systems Journal 38(4), 508-530.

Arnold, K. (2010) 'Signals: Applying academic analytics.' Educause Quarterly, 33(1). Available at: http://www.educause.edu/ero/article/signals-applying-academic-analytics (Accessed: 4 May 2014).

Buckingham Shum, S. (2012) Learning Analytics. UNESCO Policy Brief. Available at: http://iite.unesco.org/pics/publications/en/files/3214711.pdf (Accessed: 2 February 2015).

DeJong, R. (2013) 'Why MOOCs Aren't So Cheap ... for Colleges.' Fiscal Times, 18 September 2013. Available at: http://www.thefiscaltimes.com/Articles/2013/09/18/WhyMOOCs-Arent-So-Cheap-Colleges (Accessed: 3 September 2015).

Dix, A., Finlay, J., Abowd G. and Beale, R. (2004) Human-Computer Interaction, third edition. Upper Saddle River, N.J: Prentice Hall. ISBN 0-13-239864-8 http://hcibook.com/e3

Dix, A. and Leavesley, J. (2015) ‘Learning Analytics for the Academic: An Action 
Perspective.' In: Journal of Universal Computer Science (JUCS), 21(1), 48-65. Available at: http://www.hcibook.com/alan/papers/JUCS-action-analytics-2015/ (Accessed: 22 February 2016).

Dix, A. (2015) 'More than one way to flip a class: learning analytics for mixed models of learning.' APT 2015, Greenwich, 7th July 2015. Available at:

http://alandix.com/academic/papers/apt2015-more-than-one-way/ (Accessed: 22 February 2016).

Dix, A. (2015b) 'Reuse of MOOCs: bringing online content back to the classroom.' Alt-C 2015. Available at: http://alandix.com/academic/papers/altc2015-reuse-of-moocs/ (Accessed: 22 February 2016).

Estes, M., Ingram, R. and Liu, J. (2014) 'A Review of Flipped Classroom Research, Practice, and Technologies.' International HETL Review, 4, 29 July 2014. Available at:

https://www.hetl.org/a-review-of-flipped-classroom-research-practice-and-technologies/ (Accessed: 22 February 2016).

Fox, J. (2010) What does a corporate web video cost? OMM blog, 3 March 2010. Available at: http://onemarketmedia.com/2010/03/03/what-does-a-web-video-cost-25-factors-withprices-that-affect-video-production-costs/ (Accessed: 7 July 2015).

Hamdan, N., McKnight, P., McKnight, K. and Arfstrom, K. (2013) A Review Of Flipped Learning. Flipped Learning Network. Available at:

http://www.flippedlearning.org/cms/lib07/VA01923112/Centricity/Domain/41/LitReview Flipp edLearning.pdf (Accessed: 30 October 2015).

HESA (2015) Table T1a - "Participation of under-represented groups in higher education: UK domiciled young full-time first degree entrants 2013/14.' UKPIs: Widening participation of under-represented groups (tables T1, T2). Higher Education Statistics Agency. Available at: https://www.hesa.ac.uk/pis/urg (Accessed: 30 October 2015).

Hibbert, M. (2014) 'What Makes an Online Instructional Video Compelling?' EDUCAUSE Review Online, 7 April 2014. Available at: http://www.educause.edu/ero/article/what-makesonline-instructional-video-compelling (Accessed: 22 February 2016).

Hollands, F. and Tirthali, D. (2014) 'Resource Requirements and Costs of Developing and Delivering MOOCs.' The International Review of Research in Open and Distributed Learning, 15(5). Available at: http://www.irrodl.org/index.php/irrodl/article/view/1901/3069 (Accessed: 3 September 2015).

Hollands, F. and Tirthali, D. (2014b) 'MOOCs: Expectations and Reality.' Online Learning Insights, 20 May 2014. Available at: https://onlinelearninginsights.wordpress.com/tag/moocsexpectations-and-realities/ (Accessed: 7 September 2015).

IDF (2015) 'Interaction Design Foundation.' Available at: https://www.interaction-design.org/ (Accessed: 30 October 2015).

Kerr, J., Houston, S., Marks, L. and Richford, A. (2015) 'Building and Executing MOOCs: A practical review of Glasgow's first two MOOCs (Massive Open Online Courses).' University of Glasgow. Available at: 
http://www.gla.ac.uk/colleges/socialsciences/staff/learningandteaching/mooc/ (Accessed: 3 September 2015).

Long, P. and Siemens, G. (2011) 'Penetrating the fog: Analytics in learning and education.' EDUCAUSE Review, 46(5).

Schell, J. (2012) Choreography of a Flipped Classroom, Turn to your Neighbour, Peer Instruction blog. Available at: http://blog.peerinstruction.net/2012/07/03/choreography-of-aflipped-classroom.html (Accessed: 22 April 2015).

The Guardian (2015) 'My students have paid £9,000 and now they think they own me.' The Guardian, Higher Education Network, 18 December 2015. Available at:

http://www.theguardian.com/higher-education-network/2015/dec/18/my-students-have-paid9000-and-now-they-think-they-own-me?CMP=Share AndroidApp Gmail (Accessed: 22 February 2016).

UCL (2008) Information Behaviour of the Researcher of the Future. UCL, 11 January 2008. (Report to JISC and the British Library on the "Google Generation") Available at: http://www.jisc.ac.uk/media/documents/programmes/reppres/gg final keynote 11012008.p df (Accessed: 22 April 2015).

UK Gov. (2015) Fulfilling Our Potential: Teaching Excellence, Social Mobility And Student Choice. Department of Business, Innovation and Skills, consultation document, HMSO. November 2015. Available at: https://www.gov.uk/government/consultations/highereducation-teaching-excellence-social-mobility-and-student-choice (Accessed: 10 February 2016). 